Article

\title{
Appropriate Technology for Access to Universal Basic Services: A Case Study on Basic Electricity Service Provision to Remote Communities in the Napo River Basin
}

\author{
Laura Del-Río-Carazo ${ }^{1, *(\mathbb{D})}$, Santiago Iglesias-Pradas ${ }^{1}$, Emiliano Acquila-Natale ${ }^{1}$ (D) \\ and José Gabriel Martín-Fernández ${ }^{2}$ \\ 1 Departamento de Ingeniería de Organización, Administración de Empresas y Estadística, ETSI de \\ Telecomunicación, University Politécnica de Madrid, Av. Complutense 30, 28040 Madrid, Spain; \\ s.iglesias@upm.es (S.I.-P.); emiliano.acquila@upm.es (E.A.-N.) \\ 2 Acciona.org Foundation, Av. de Europa 18, 28108 Alcobendas, Spain; \\ josegabriel.martin.fernandez@acciona.com \\ * Correspondence: laura.delrio@upm.es
}

Citation: Del-Río-Carazo, L.; Iglesias-Pradas, S.; Acquila-Natale, E.; Martín-Fernández, J.G. Appropriate Technology for Access to Universal Basic Services: A Case Study on Basic Electricity Service Provision to Remote Communities in the Napo River Basin. Sustainability 2022, 14 , 132. https://doi.org/10.3390/ su14010132

Academic Editor:

César Martín-Gómez

Received: 14 October 2021

Accepted: 21 December 2021

Published: 23 December 2021

Publisher's Note: MDPI stays neutral with regard to jurisdictional claims in published maps and institutional affiliations.

Copyright: (C) 2021 by the authors. Licensee MDPI, Basel, Switzerland. This article is an open access article distributed under the terms and conditions of the Creative Commons Attribution (CC BY) license (https:// creativecommons.org/licenses/by/ $4.0 /)$.

\begin{abstract}
Appropriate technologies (ATs) refer to technologies that are controlled by the communities that benefit from their implementation. Technologies have become a fundamental element in projects aiming to solve problems related to poverty and access to basic needs in some areas in emerging countries, and appropriation of these technologies is necessary to ensure effective transfer of knowledge and sustainability. However, due to the lack of consensus on the definition of ATs, there is a need to clarify and define the scope and boundaries of the term to facilitate the implementation of technology in projects in developing countries. This study addresses this gap by means of a scoping review, which presents a detailed analysis of 17 journal articles (from an initial selection of 95 articles) and provides a comprehensive definition of ATs. To guide AT-oriented interventions in technology-intensive cooperation projects, this study proposes an Action Framework based on that definition of ATs. The Action Framework provides guidance on how to implement technology in these projects to ensure that the technology is appropriated. To facilitate the understanding of the Action Framework, the study showcases its application in a real project of rural electrification in the Peruvian Amazon Rainforest.
\end{abstract}

Keywords: appropriate technology; scoping review; cooperation projects; sustainability; action framework; case study

\section{Introduction}

In 2015, coinciding with the end of the MDGs, the General Assembly of the United Nations (UN) established the 2030 Agenda for Sustainable Development, with the goal of guaranteeing equality between people, protecting the planet and ensuring prosperity. The 2030 Agenda sets out the eradication of poverty, protection of the planet and guaranteeing peace and justice as the world's main challenges, and defines seventeen Sustainable Development Goals (SDGs) [1].

The concept of sustainable development aims at the long-term stability of the economy and the environment through the identification and integration of economic, environmental and social problems throughout the decision-making process [2,3]. From a different perspective, a sustainable development is one that meets the needs of the present time without compromising the ability of future generations to meet their own needs [4].

The SDGs, unlike the MDGs, are set from a universal point of view, involving all countries and institutions, considering the reality of the most vulnerable and remote communities and guaranteeing the sustainability of the model. The achievement of these objectives depends on the development of actions at three levels: worldwide actions to 
guarantee leadership, resources and solutions; actions at the local level, by involving institutions, government regulatory frameworks and cities; and actions at the level of individuals, including the youth, the media, the private sector and the academic world [5].

In this context, the SDGs provide a new broad framework for action in projects aimed at ensuring access to the basic services defined in the Declaration of Human Rights [6]: water, energy, food, health, education, sanitation and housing. These kinds of projects have gained relevance as the SDGs become a key issue in inclusive development projects [7]. Community projects in emerging countries help address these needs and bring about notable improvements in the community's quality of life. However, they present a fundamental challenge: the transfer of knowledge and technology [8]. The challenge of technology-intensive, community-oriented projects is, therefore, to ensure that the interventions are carried out according to the needs of the population and that the continuity of the projects is viable through the training of the community members [9].

Appropriate technologies (ATs) are an essential component of technology-intensive, community-based projects that help meet the community's needs [10]. Introduced by Schumacher [11], ATs were initially defined as small-scale labor-intensive, low-capital, energy-efficient technologies controlled by the local community. However, the increasing relevance of sustainability-related concepts has opened the debate about the definition and characteristics of ATs. Furthermore, there are different views of ATs depending on the field of study (medicine, economics, sustainability and others) or whether the focus should be put on technology or the people [12-14].

This research aims to contribute to this debate by clarifying the concept as the basis for the definition of an Action Framework to design and implement technology in technologyintensive cooperation projects. While previous studies on ATs offer limited approaches to the topic $[15,16]$, this research provides a complete definition of ATs and a comprehensive view of all the stages involved in the implementation of an AT project (initiation, planning, implementation and closure).

To achieve this objective, the research identifies the main elements of ATs and studies the evolution of the concept over time. The identification of elements is performed by means of a scoping review, given its effectiveness and usefulness in scoping and mapping existing research on a topic [17]. As a novelty, the definition of ATs differentiates between the necessary elements and the intrinsic characteristics of the technologies for their appropriateness.

By combining the definition of ATs with a project management view, the study proposes a novel Action Framework that helps understand how to successfully implement AT-based projects. Beyond a mere theoretical formulation, a case study illustrates the application of the Action Framework and its usefulness in ensuring the appropriateness of technology in technology-intensive, community-based projects.

The remainder of this study is organized as follows. Section 2 details the methodology followed to develop the scoping review and summarizes the main findings of the review as the basis for the Action Framework, which is formulated in Section 3. Section 4 presents a case study on the application of the Action Framework to a project involving the use of ATs. Section 5 discusses the main findings from the case study. Section 6 summarizes the main conclusions and provides guidelines for future research on ATs.

\section{Methodology}

To better understand the concepts of ATs and subsequently generate an Action Framework for this type of project, the study carries out a literature review. Among the different existing types of the literature review [18], this study proposes a scoping review. Scoping reviews help clarify key concepts and definitions in the literature, identify key characteristics or factors related to a concept and identify and analyze knowledge gaps $[18,19]$. Essentially, scoping reviews are similar to systematic reviews, and the main difference is that in scoping reviews, the objectives are broader and more comprehensive, whereas systematic reviews are narrow in focus and are guided by specific research questions [20]. Therefore, a scoping 
review is more appropriate for an assessment of the current status of research on a topic, and it is deemed more appropriate to achieve the goals of this research while serving as the ground for more profound revision in the future (i.e., a systematic review). This scoping review follows Arksey and O'Malley's [21] five-stage framework: (1) identification of the research question, (2) identification of relevant studies, (3) selection of studies, (4) data charting and (5) collation, summarizing and reporting of the results.

\subsection{Initial Research Questions}

The main objective of the scoping review is to identify the different topics pertaining to the realm of ATs. Consequently, the study proposes the following research questions for the scoping review:

- SR-RQ1: How to define ATs, and what aspects should this definition cover?

- SR-RQ2: Has the concept of ATs changed over time? If so, how?

- SR-RQ3: Can we identify gaps in the research on ATs?

\subsection{Identification of Relevant Studies}

The identification of relevant studies has been performed using the Web of Science database. Three different search options (Table 1) have been considered: the first two focus on articles including the term Appropriate Technology as a keyword-including both terms separately and jointly. Because the focus of this study is the use of ATs in community-based projects, an additional filter has been applied to exclude studies unrelated to the following subjects: sustainability, community actions, the bottom of the pyramid, technology transfer, developing countries; to do so, the filter includes the following categories: economics, multidisciplinary sciences, business, management, social sciences interdisciplinary. The third search option seeks to identify articles that include the term AT near the word "definition", or some variation of the word. Additional inclusion criteria required that the articles were written in English and published after 1973, the date of Schumacher's [11] initial definition.

Table 1. Queries Scoping Review.

\begin{tabular}{|c|c|c|c|}
\hline Queries & Type & Categories & Web of Science \\
\hline "Appropriate technologies" & Keyword & $\begin{array}{l}\text { ECONOMICS, MULTIDISCIPLINARY } \\
\text { SCIENCES, BUSINESS, } \\
\text { MANAGEMENT, SOCIAL SCIENCES } \\
\text { INTERDISCIPLINARY }\end{array}$ & 35 \\
\hline Appropriate technologies & Keyword & $\begin{array}{l}\text { ECONOMICS, MULTIDISCIPLINARY } \\
\text { SCIENCES, BUSINESS, } \\
\text { MANAGEMENT, SOCIAL SCIENCES } \\
\text { INTERDISCIPLINARY }\end{array}$ & 39 \\
\hline "Appropriate technologies" & Theme (Near defin *) & All & 21 \\
\hline
\end{tabular}

\subsection{Study Selection}

The process of article selection has followed the PRISMA-Statement [22], as shown in Figure 1. The initial search using the three queries and the inclusion criteria returned 95 articles. Of those, 36 duplicate articles from the 3 sets of search results have been removed. Three of the authors of this study conducted a screening of the resulting 59 studies by separately and independently reviewing their titles and abstracts and filtering those that were related to community-based projects. Adopting a majority consensus (i.e., two or three reviewers considered that the article involved community-based projects), only 29 articles matched the filtering criterion. Upon thorough examination, the articles that did not include a definition of ATs were then removed. As a result, a total of 17 studies were included in the final set. 


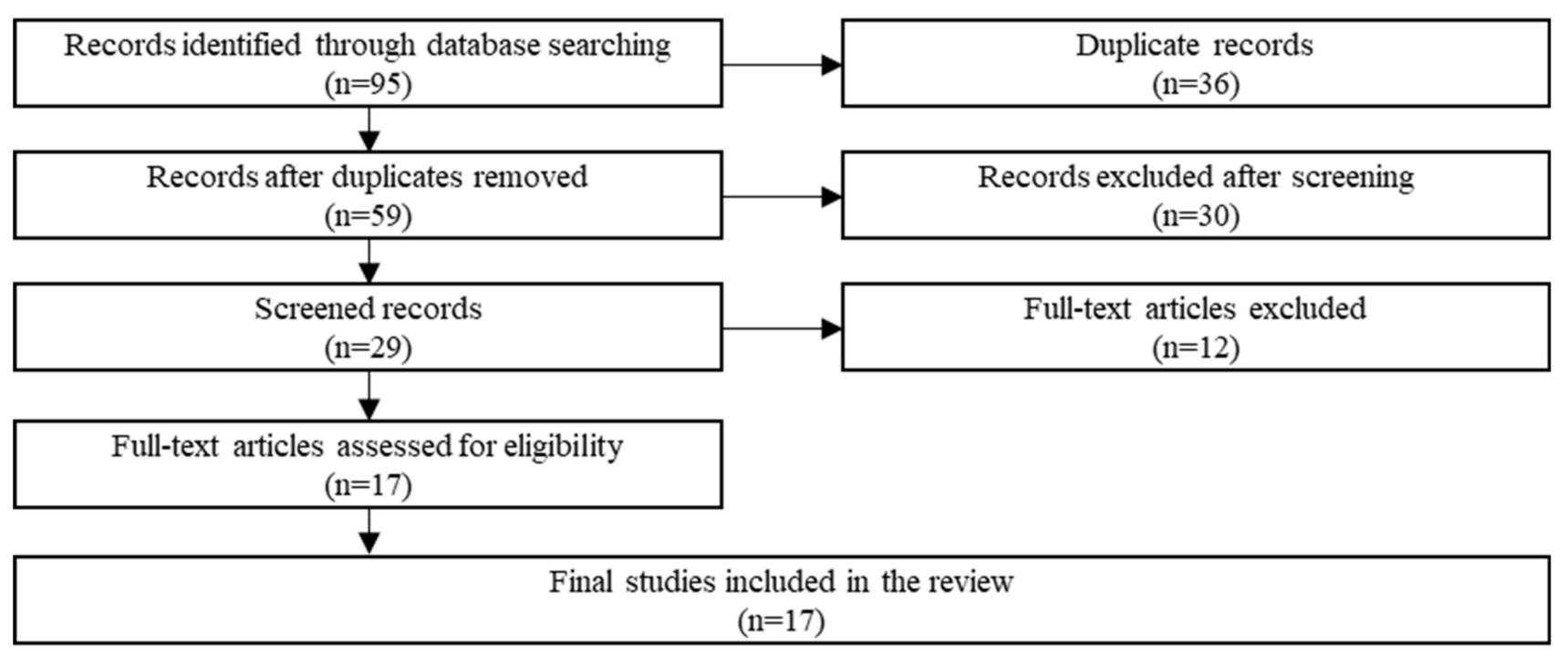

Figure 1. PRISMA flow diagram for article selection.

\subsection{Data Charting}

The execution of community-based projects involving ATs follow the phases of a project, albeit requiring an adaptation to the specific context of the application. The phases identified by traditional project management are: initiation, in which the problem or opportunity is identified, possible solutions are planned, objectives are set and the scope and depth of the project are defined; planning, in which the project timeline is defined, resources are selected and budgets are estimated; execution, in which tasks are distributed among the different team members, who get training in the required skills, and the work plan is organized by establishing the necessary communication flows; the final stage is closure, in which the project is analyzed, documented and the team's performance is analyzed [23-25].

The definitions and characteristics of ATs found in prior research have been adapted to AT-based projects and framed according to these phases but, to facilitate the understanding of the Action Framework, the traditional phases will be simplified based on the reviewed literature (Figure 2). The first phase (initiation) involves the identification of the goals and scope of the project $[16,26]$, and it is followed by the selection of the necessary resources (planification) to develop the project [26]; at this stage, it is necessary to select and allocate the economic, human and material resources that guarantee the long-term viability of the project $[7,16]$, paying special attention to technology-related resources [26]. Once these phases are completed, the next stage (execution) comprises the execution of the project [16]. After implementation, it is necessary to analyze the results and impact of the project (closure), which must be in line with the goals set during the first phase [16,26].

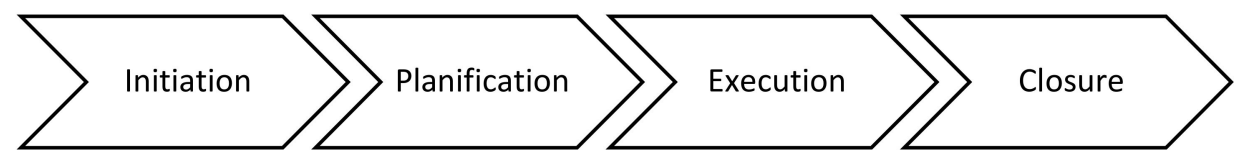

Figure 2. Phases of technology-intensive cooperation projects (AT-based projects).

From the analysis of the final set of studies, and after grouping terms with identical meanings, fourteen topics emerged (Table 2), each of which was included in one of the stages of the AT-based project execution framework presented above. The criterion for topic inclusion observes that (1) the subtopics must be quoted verbatim in the definition of ATs, or (2) the topics are identified as characteristics of ATs outside the definition across the text of the article. 
Table 2. Summary of the studies included in the scoping review.

\begin{tabular}{|c|c|c|c|c|c|c|c|c|c|c|c|c|c|c|c|c|}
\hline \multirow{2}{*}{ Author(s) } & \multirow{2}{*}{$\mathbf{T}$} & \multirow{2}{*}{ Scope } & \multicolumn{3}{|c|}{ Initiation } & \multicolumn{7}{|c|}{ Planification } & \multicolumn{2}{|c|}{ Execution } & \multicolumn{2}{|c|}{ Closure } \\
\hline & & & 1 & 2 & 3 & 4 & 5 & 6 & 7 & 8 & 9 & 10 & 11 & 12 & 13 & 14 \\
\hline Segal (1992) [27] & $\mathrm{T}$ & DEV & + & & $\boldsymbol{v}$ & & & & $\boldsymbol{v}$ & $\boldsymbol{\nu}$ & $\boldsymbol{v}$ & $\boldsymbol{V}$ & & + & + & \\
\hline AI-Ali (1995) [16] & $\mathrm{T}$ & $\mathrm{TT}$ & & & & & & & & & & $\boldsymbol{V}$ & & & & \\
\hline Kaplinsky (2011) [28] & $\mathrm{T}$ & $\mathrm{BoP}$ & & & $\boldsymbol{V}$ & $\checkmark$ & $\boldsymbol{v}$ & & & & $\boldsymbol{v}$ & & & $\boldsymbol{v}$ & & $\checkmark$ \\
\hline Guimón and Guimón (2012) [29] & $\mathrm{T}$ & TT & $\boldsymbol{\nu}$ & $\boldsymbol{v}$ & & $\boldsymbol{\nu}$ & $\boldsymbol{\nu}$ & & $\boldsymbol{\nu}$ & $\boldsymbol{\nu}$ & & $\boldsymbol{v}$ & $\boldsymbol{v}$ & $\boldsymbol{\nu}$ & & $\boldsymbol{\nu}$ \\
\hline Verharen et al. (2013) [30] & $\mathrm{T}$ & CA & & & $\boldsymbol{v}$ & $\checkmark$ & & + & $t$ & $t$ & $t$ & + & $t$ & + & $\boldsymbol{V}$ & t \\
\hline Park and Ohm (2015) [31] & $\mathrm{T}$ & SUST & $\boldsymbol{v}$ & & & & & & & & & & $\checkmark$ & $\checkmark$ & $\checkmark$ & \\
\hline Tharakan (2015) [10] & $\mathrm{T}$ & SUST & $\boldsymbol{v}$ & $\boldsymbol{V}$ & & & & $\boldsymbol{V}$ & + & + & + & $\boldsymbol{V}$ & $\boldsymbol{V}$ & $\checkmark$ & $\boldsymbol{V}$ & $\boldsymbol{v}$ \\
\hline Tharakan (2015) [32] & $\mathrm{T}$ & SUST & $\checkmark$ & $\checkmark$ & & & & $\boldsymbol{V}$ & $t$ & $t$ & $t$ & $\boldsymbol{V}$ & $\checkmark$ & $\boldsymbol{v}$ & $\boldsymbol{V}$ & $\checkmark$ \\
\hline Sorensen and McBean (2015) [15] & $\mathrm{E}$ & SUST & & & & $\boldsymbol{v}$ & & & & & & $\boldsymbol{V}$ & $\boldsymbol{V}$ & & & \\
\hline Pattnaik and Dhal (2015) [14] & $\mathrm{E}$ & SUST & & $\boldsymbol{v}$ & $\boldsymbol{v}$ & & & & & & & & + & + & + & t \\
\hline Verharen et al. (2017) [13] & $\mathrm{E}$ & TT & & $\checkmark$ & & & & & & & & & $\checkmark$ & & & 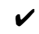 \\
\hline Botchie et al. (2018) [33] & $\mathrm{E}$ & TT & & & + & $\boldsymbol{v}$ & $\boldsymbol{v}$ & & & + & $t$ & + & $\boldsymbol{V}$ & & & \\
\hline Wensing et al. (2018) [8] & $\mathrm{E}$ & CA & $\checkmark$ & & & $\checkmark$ & & & & & & & + & $\checkmark$ & & \\
\hline Bhattacharjya et al. (2019) [26] & $\mathrm{E}$ & TT & + & t & $\boldsymbol{v}$ & & t & + & & & & + & t & & & t \\
\hline Shin et al. (2019) [7] & $\mathrm{E}$ & SUST & $\boldsymbol{v}$ & $\boldsymbol{\nu}$ & & & & & & & & $\boldsymbol{v}$ & $\boldsymbol{v}$ & & $\dagger$ & \\
\hline Lashitew et al. (2019) [34] & $\mathrm{E}$ & TT & & $\boldsymbol{\nu}$ & & & & & & & & $\boldsymbol{\nu}$ & & & & \\
\hline Patnaik (2019) [12] & $\mathrm{T}$ & SUST & & $\checkmark$ & & + & $t$ & + & + & & & + & $\checkmark$ & $\checkmark$ & & \\
\hline
\end{tabular}

$\boldsymbol{}$-Topic in definition; †-Topic in article but not in definition (characteristics) Type: T: Theoretical; EEmpirical Scope: DEV-Developing Countries; BoP-Bottom of the Pyramid; CA-Community Actions; SUSTSustainability; TT-Technology transfer Topics: 1-People-oriented; 2-Aligned with local needs; 3-Small-scale 4-Affordable; 5-Simple; 6-Adaptable and flexible; 7-Low capital investment; 8-Low-skill; 9-Laborintensive; 10-Local resources; 11-Community developed; 12-Sustainable; 13-Community improvement; 14-Maintainable.

Data charting (Table 2) includes a summary of the seventeen articles, identified by author, year, type of research (empirical or theoretical), the scope of application and main topics covered by the definition of ATs in each of the stages.

\subsection{Collation, Summary and Report of Results}

From the review, Schumacher's [11] initial definition remained mostly unchanged until the second decade of the twenty-first century, when ATs have become a more recurrent topic. Overall, the most recent literature has raised awareness about the relevance of the context of AT-based implementation projects. The year 2015 was a turning point in the development of the concept of AT, coinciding with the declaration of the SDGs. These objectives, unlike those established in the MDGs, underline that problems are interconnected and must be tackled by all countries at once.

Consequently, a big difference between articles published before and after 2015 is the shift from theoretical to empirical approaches to incorporate topics included in the SDGs. Theoretical articles convey a very broad and perhaps unrealistic overview of how projects should ideally be developed, whereas empirical articles focus on the specific characteristics of ATs and phases of AT-based projects identified in Section 2.4. To reconcile this gap between theory and practice, a comprehensive definition of ATs should be selected carefully and, more important, concisely - considering the number of topics included in the definition while taking into account the different stages of execution of community-based projects.

Some topics from Table 2, such as resource selection in the planification phase, have not generally been included as part of the definitions but are often mentioned as characteristics of ATs. Most definitions involve topics related to initiation, execution and closure, even though empirical studies generally omit the latter.

Observing topic relevance, it is possible to establish a definition and a list of characteristics that serve as a practical model for AT-based projects. This definition should focus on the initiation, execution and closure phases but also include characteristics related to planification. As shown in Table 2, some topics (e.g., low capital investment, low-skill and labor-intensive), are only covered in articles published before 2010, and they are also rarely mentioned in empirical studies; therefore, they may be considered less relevant and could be excluded from a comprehensive definition. Further, topics related to technology selection (i.e., intrinsic characteristics of ATs), are particular to the context of the project [10]; 
therefore, they could also be excluded from the definition, even though they still must be considered as characteristics of ATs.

From the above, this study proposes the following definition of ATs: "Appropriate technologies for community-based projects are technologies oriented towards the people of the community to address their needs, in small scale projects that are sustainable and maintainable, in which community members are engaged in the development and implementation and have a positive impact on the community. Appropriate technologies should be affordable, simple, adaptable and use local resources." This definition of ATs provides a broad but realistic thematic coverage while leaving room for the implementation of AT projects in specific contexts. Table 3 offers a more detailed explanation of the different topics and characteristics covered by the definition of ATs.

Table 3. Topics (T) and characteristics (C) of ATs.

\begin{tabular}{|c|c|c|c|}
\hline Term & Type & Phase & Definition \\
\hline People-oriented & $\mathrm{T}$ & I & $\begin{array}{l}\text { People are at the center of the development process to } \\
\text { reduce their vulnerabilities and equip them with } \\
\text { capabilities that will enable them to improve their quality } \\
\text { of life }[7,32]\end{array}$ \\
\hline Aligned with local needs & $\mathrm{T}$ & I & $\begin{array}{l}\text { The design of technological solutions is adapted to the } \\
\text { context of the community, by first identifying the } \\
\text { particularities of each area and then identifying which } \\
\text { solution best fits the context }[26,34] \text {. }\end{array}$ \\
\hline Small scale & $\mathrm{T}$ & I & $\begin{array}{l}\text { Technology that involves a limited number of beneficiary } \\
\text { agents in order to test the viability of actions, redefine } \\
\text { them on an ongoing basis and achieve real results in } \\
\text { practice by adjusting to the needs and circumstances of } \\
\text { specific communities }[12,28] \text {. }\end{array}$ \\
\hline Community developed & $\mathrm{T}$ & $\mathrm{E}$ & $\begin{array}{c}\text { Community members are engaged in project development } \\
\text { and implementation. The project empowers the } \\
\text { community by enabling the population to manage the } \\
\text { interventions }[8,10] \text {. }\end{array}$ \\
\hline Sustainable & $\mathrm{T}$ & $\mathrm{C}$ & $\begin{array}{c}\text { Ability to meet the needs of the community without } \\
\text { compromising the ability of future generations to meet } \\
\text { their needs [8]. }\end{array}$ \\
\hline Community improvement & $\mathrm{T}$ & $\mathrm{C}$ & $\begin{array}{l}\text { Positive impact on the quality of life of the community as } \\
\text { a result of the intervention }[7,30] .\end{array}$ \\
\hline Maintainable & $\mathrm{T}$ & $\mathrm{C}$ & $\begin{array}{c}\text { The technology can be repaired and controlled over time } \\
\text { in a simple way without requiring a very high } \\
\text { capacitation or intensive training [10]. }\end{array}$ \\
\hline Local resources & $\mathrm{C}$ & $\mathrm{P}$ & $\begin{array}{c}\text { The resources involved in the project come from the } \\
\text { community level [34]. }\end{array}$ \\
\hline Affordable & $\mathrm{C}$ & $\mathrm{P}$ & $\begin{array}{l}\text { The population can access the solution without it } \\
\text { representing a significant percentage of their income and, } \\
\text { therefore, making it impossible for them to access other } \\
\text { basic services in exchange }[30,33]\end{array}$ \\
\hline Simple & $\mathrm{C}$ & $\mathrm{P}$ & $\begin{array}{l}\text { The demands for high skills are minimized, not only in } \\
\text { the production process but also in the management, raw } \\
\text { material supply, financing or marketing }[28,29] \text {. }\end{array}$ \\
\hline Adaptable and flexible & $\mathrm{C}$ & $\mathrm{P}$ & $\begin{array}{l}\text { Able to change and made suitable for different conditions } \\
\text { in an easy way }[12,26] .\end{array}$ \\
\hline
\end{tabular}

Type: T: Theoretical; E-Empirical. Phase: I-Initiation; P-Planification; E-Execution; C-Closure.

\section{Action Framework for Technology-Intensive Cooperation Projects}

Considering the above definition of ATs, we propose an Action Framework for technology-intensive cooperation projects that conciliates both the fundamental topics and characteristics of ATs and the phases of this type of project. The main objective of the Action Framework is to guide the project plan and implementation in such a way that it can 
be ensured that the intervention addresses the community's needs, is sustainable over time and has a positive impact on the community. According to Table 3, the Action Framework comprises the following stages (Figure 3).

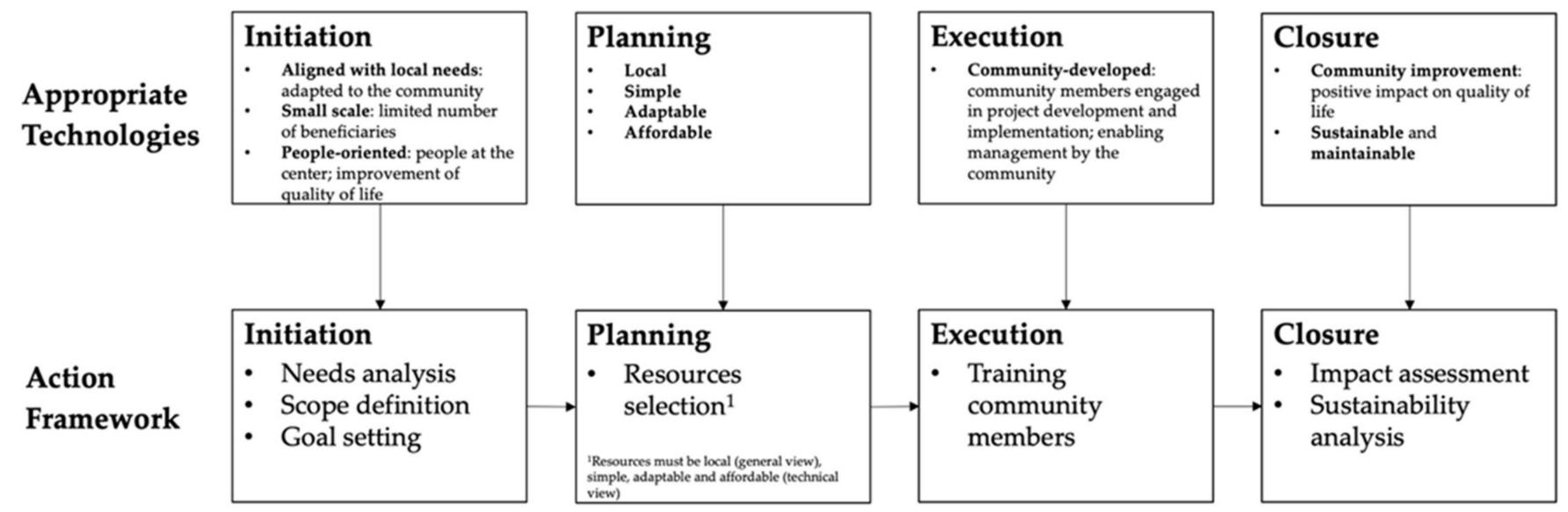

Figure 3. Action Framework for technology-intensive cooperative projects.

Initiation: Adequately tailoring the solution to the beneficiaries of the project involves a correct identification of their needs (needs analysis) [12,26], which ensures that the project is aligned with the local needs. Upon this identification, it is possible to define the scope of the project (scope definition) [10,26]. The scope should be narrow enough to include a limited number of beneficiary agents, which facilitates adaptation to the needs of the community. As a result of the needs identification and scope definition, it is necessary to set the goals of the project (goal setting) [16] in such a way that the project may put people at the center of the development process and enable them to improve their quality of life.

Planification: After defining the objectives of the project such that it is aligned with the needs of the community, it is necessary to select the resources that will be involved in the project (resources selection) $[14,33,34]$. At the general level, the resources should preferably be local [10]; at the technical level, the resources should also be simple, adaptable and affordable [29,32]. From our definition, the technologies should be local, affordable, simple and adaptable and flexible.

Execution: This phase comprises the development and implementation of the project. AT-based projects should ensure that community members are engaged in that development and implementation, enabling them to manage the interventions. The engagement and enabling of community members is only possible through adequate training in the different activities that are necessary for the correct implementation of the project (training community members) $[8,10,26]$.

Closure: At the end of the project, the implementation should have a positive impact on the quality of life of the community, which makes it necessary to analyze the results [16] to ensure that the needs of the community are being met and to perform an assessment of the impact of the project (impact assessment) [27] that confirms that the project is having a positive impact on the community. In AT-based projects, this assessment must be necessarily complemented by an analysis of the sustainability of the project (sustainability analysis) [29] to ensure that the project can be maintained over time in a sustainable way.

\section{Case Study: The Luz en Casa Amazonía Project}

This section showcases the application of the Action Framework in a real technologyintensive cooperation project of remote areas rural electrification in Peru. The project aims at providing clean basic electricity service(s) to remote communities in the Amazonia (Amazon rainforest), with special attention to their specific needs and the particularities of the location. The project falls within the scope of the Action Framework for various reasons: (1) it is tailored to the protected environment in which these communities reside, and the 
project design is targeted at a small scale; (2) the project is expected to be developed by the community, involving agents with different levels of responsibility; (3) the project plan includes the capacitation and training of different users and managers; (4) the model for energy provision is maintainable and sustainable; and (5) by achieving the project's goal, a positive impact on the communities is expected. The following subsections introduce the context of the project and detail its execution within the framework presented in Section 3.

\subsection{Project Overview}

The project was led and developed by acciona.org, the corporate foundation of ACCIONA, one of the leading Spanish companies in infrastructure, renewable energies, water and services development and management. Acciona.org specializes in providing basic energy, water and sanitation services to remote communities. The project presented in this case study, Luz en Casa Amazonía, is part of the broader rural electrification initiative "Luz en Casa", which makes affordable electricity available to more than 64,000 people in Peru, Mexico, Panama and other locations using solar photovoltaic energy. The project (Table 4) has been deployed, to this date, in collaboration with Universidad Politécnica de Madrid (UPM) mainly, as well as the ICAI Engineers for Development Foundation (FICAID), Comillas Pontifical University of Madrid's Institute for Research in Technology (IIT) and ACCIONA Microenergía Perú (AMP) —a Peruvian non-profit civil association promoted by acciona.org to develop its service delivery models in the country as the implementer in situ. The project has been co-financed by the Peru National Fund of Scientific and Technological Development and Technological Innovation (FONDECYT) and the Spanish Agency for International Development Cooperation (AECID).

Table 4. Luz en Casa Amazonía project overview.

\begin{tabular}{cc}
\hline Project Title & Luz en Casa Amazonía \\
\hline Beneficiaries \\
$\begin{array}{c}\text { Project Period } \\
\text { Institutions }\end{array}$ & Residents in the Peruvian Napo, Ucayali and Amazonas River basins \\
& 2016-2021 \\
acciona.org & Acciona Microenergía Perú (AMP) \\
& Universidad Politécnica de Madrid (UPM) \\
Funding bodies & ICAI Engineers for Development Foundation (FICAID) \\
& Comillas Pontifical University of Madrid's Institute for Research in Technology (IIT) \\
Spanish Agency for International Development Cooperation (AECID)
\end{tabular}

The geography of Peru is defined by the Andes range, which unfolds to the west towards an arid coast and to the east towards the Amazon rainforest. Overall, Peru offers one of the largest biological wealth and variety in the world, as well as material resources. With a population of 32.51 million [35]. Peru had a poverty rate of 30.1 percent in 2020, with an increase of 9.9 percent from the previous year due to the effects of the COVID-19 pandemic outbreak. Electric energy access extends to 98.35 percent of the country, but this figure drops down to 92.45 percent in rural areas; in the Amazon rainforest area; only 82.7 percent of the population has access to electric energy [35]; that is, about 1 in 5 people do not have access to energy.

In 2016, acciona.org started deploying solar home systems (SHS) in the Peruvian Amazon rainforest to provide basic energy access using renewable sources with the goal of improving the living conditions of people in underdeveloped and remote areas. Initially, the project began with a pilot to validate the technology and management model. The pilot was implemented in 61 households and was based on the planned multi-actor management model [36], with special consideration to affordable fees for the service and the technology systems. After the implementation of the pilot, its acceptance by the community was validated using satisfaction surveys; satisfaction with the use of the SHS was 100 percent, 88 percent of the users considered that it was easy to install and 98 percent said that it 
had resulted in savings in their energy expenditure. The project was then progressively implemented in other communities along the Peruvian stretch of the Napo River: a first scaling up was developed to benefit an additional 350 households in 2018; and a second scaling up benefited an additional 1107 households in the Napo River basin, as well as the Ucayali and Amazonas River basins, between 2020 and 2021. To this date, the project provides energy to a total of 7365 people across 51 communities in the Peruvian Amazon rainforest under the social enterprise ACCIONA Microenergía Perú (AMP).

\subsection{Application of the Action Framework: Project Development \\ 4.2.1. Initiation}

Needs identification: Because the objective of the project was to provide community members with access to energy, it was necessary to perform an analysis of the needs and problems of the study area and its communities. The most relevant challenges presented by rural electrification in remote areas, such as the one in the case study, are the following [37]:

- Lack of interest of energy/electricity distributors (public and private) due to low demand and high investment, operation and maintenance costs: the low energy demand of the communities in the area means that energy distribution companies have little interest in working in these areas because of the difficulty to recover the high investment required to provide access to energy to the population and cover the operation and maintenance costs.

- Uncertain sustainability of project execution: the Peruvian Amazon rainforest is a remote territory that can only be accessed by the river, with high ecological value and extremely hot and rainy weather; consequently, the logistics of energy distribution and management are very complex.

- Lack of energy-related and socioeconomic information about the population of isolated communities, which makes it difficult to make decisions for the implementation of programs that have an impact on them. Gathering information from isolated communities can reveal the reality of these areas, and thus allow the design of solutions adapted to each area and region within the framework of the universalization of access to energy.

Scope definition and goals setting: The design of an adequate and affordable solution to overcome these challenges and improve the quality of life of the community members entails tailoring the solution to the location and how it is accessed, as well as to the complex climate conditions, in a way that the project is economically sustainable despite the beneficiaries' low energy demand and low income, while relying on the communities to meet their specific needs. The Luz en Casa Amazonía program addresses these issues by adopting an electricity supply model based on a fee-for-service approach, user participation, shared responsibility and multi-stakeholder management.

From the above, the initiation (pilot) phase of the project is focused on the needs of the people and the specific communities where the intervention is being carried out. Subsequently, it is expanded to other communities through small-scale projects, redefining the actions for each of the interventions and adjusting them to the needs of the communities. Therefore, the intervention met the appropriate technology requirements outlined in the Action Framework for the first phase of the project.

\subsubsection{Planification}

Resources selection: The second stage of the Action Framework comprises the planning of the human and material resources involved in the project. According to the framework, the resources should ideally be local, although some special considerations may apply depending on whether the resources are human or material. When considering human resources, the project considers a model of agents; more specifically, a multi-actor management model that includes local organizations acting as service providers in the area of operation (in this case, AMP), end-users involved in the fulfillment of the service conditions, payments and basic maintenance of the facilities, who participate in the repre- 
sentative bodies of their communities (the Committees), and the micro-businesses that are promoted between local small entrepreneurs (so-called Centro Luz en Casa, CLC), who are specifically trained to offer technical maintenance services and sales of equipment to ensure the optimal use of the SHS.

Once the operation stage starts, the Committees oversee the collection of user fees, making the payment at the micro-businesses (CLC) and then distributing the receipts to users. In addition to this administrative work, the Committees are in charge of the preventive maintenance of the facility, carrying out visual inspections and sending information about the status of the systems to AMP. If an incident occurs, such as a failure, users must bring the equipment to the CLC in the area (the location of the CLCs was strategically chosen so that they were compatible with the community members' daily life activities; the initial pilot included one CLC, followed by the creation of one and two more CLCs in the first and second scaling up of the project, respectively), where a repair order is created; the repair report is incorporated into the AMP database to perform monitoring and tracking of system failures globally.

Regarding material resources, the use of technological materials predominates and, following the recommendations of the framework for action, it is important to try to ensure that these technologies are simple, affordable, adaptable, flexible and, as mentioned above, local. To satisfy these requisites, the proposed solution includes third-generation solar home systems (SHS) that stand out for their portability, ease of installation due to their plugand-play capabilities and ease of maintenance; in addition, they do not generate pollution, unlike the diesel generators, oil lamps and candles commonly used by local inhabitants. The service provided by Luz en Casa consists of the SHS together with the solar lighting (three energy-efficient lamps) and connections for communication and entertainment compatible devices (cell phone charger and TV or radio), with an autonomy of at least 4 hours a day. A $50 \mathrm{~W}$ solar panel, a 10.5 Ah battery and a charge controller are used to avoid overcharging and over-discharging of the battery. The plug-and-play architecture of the system allows anyone to install it after basic training and use it anywhere without the need to deploy any additional infrastructure, which allows high flexibility for the users. The systems feature pay-as-you-go (PAYG) functionalities that simplify the payment process for users and thus increase the pay-as-you-go rate, facilitating energy distribution and management.

For the SHS to be affordable, a payment system that grants the user the right to use the system installed in their home needs to be designed; in this model, SHS may be owned by AMP, which may be in charge of the operation and maintenance of the equipment for the entire contract period. More specifically, the business model is a fee-for-service model, known as energy-as-a-service, which includes the cross-subsidy managed by FOSE (the Electricity Social Compensation Fund), so that homes that consume the most pay a higher rate, which compensates for those paying less. In this case, FOSE compensates AMP with 80 percent of the tariff, so that the beneficiaries of this initiative only bear 20 percent of the tariff (this distribution was not arbitrary and considered two different variables: households' average expenditure in energy access prior to the implementation of the project, based on data collected during the initiation stage and the calculation of operating costs that would ensure financial sustainability of the project). Regarding technology supply, in this case the SHS is not locally sourced due to the lack of industry capable of providing the material, human and economic resources for the manufacturing of the SHS.

\subsubsection{Execution}

Training community members: The program development process begins with the identification of homes in rural villages that do not belong to an electrification plan. Once identified, AMP reviews the conditions of their access to electricity and, if they are eligible, an informative meeting of the program is scheduled. When the number of interested parties is reached, the Committee is formed. The Committee is formed by the users themselves and serves as a communication link between AMP and the community. In turn, AMP meets with the District and Provincial Municipality to report on the program and establish an 
inter-institutional collaboration agreement between the two parties. Before installation of the SHS, the members of the Committee and the users undergo a training program, and they are informed about the rights and obligations of each party, as well as the limitations and mode of use of the system, and how to proceed in the case of malfunction. The Committee members benefit from intensive training because they oversee the verification of the proper functioning of the systems and manage the program within the community. Additionally, some local entrepreneurs are assigned the role of local technicians in charge of the CLCs, and they receive specific training on how to repair the modules and the SHS equipment, collect payments from Committees, generate unblocking codes for the PAYG system and sell SHS-compatible electric devices, as well as to report payments and failures to AMP.

From the above, the project ensures that community members are engaged in its development while enabling them to manage its implementation, as required by the Action Framework. Multi-stakeholder management makes it possible to ensure the adaptation of the different models - technological and economic - to the users and creates new knowledge and skills within the community.

\subsubsection{Closure}

Impact assessment: Overall, a total of 7365 (1518 households) beneficiaries of the project in the Napo, Ucayali and Amazonas River Basins use the lighting provided by the SHS for an average of six hours a day, as of January 2021. The average operating rate of the equipment installed so far is 99.3 percent, a figure that has been steadily increasing since the start of the project. A total of 3,324,420 light hours per year have been made available to households, leading to an increase in home activities of 344,530 extra hours per year and 42,200 additional hours per year of schoolwork. The use of the SHS has caused a decrease in the use of polluting devices, and 216,133 soles/year (approximately 53,365 EUR/year) have been saved, which represents a 50 percent reduction in energy costs per household. Uncontrolled dumping caused by the use of batteries has been reduced by 8.13 tons/year, and $\mathrm{CO}_{2}$ emissions have been reduced by 158 tons/year.

Sustainability analysis: the proposed solution can be maintained over time without causing negative environmental, economic and social consequences. At the economic level, the average delay in the payment of installments is decreasing notably; in the last year, it has dropped from 68 days to 11 days (83 percent reduction). In addition, the SHSs are repaired by the CLC; therefore, they do not entail any extra cost for users over time. Both elements of the project facilitate the economic sustainability of the project. At the social level, the project benefits people in the most disadvantaged situations, favoring the environment for home study; the training of community members in management and technical skills also improves their future professional development. Finally, CLCs have carried out 80 percent of equipment repairs (13.20 percent increase in the last year), reducing travel time and costs for entrepreneurs, facilitating maintenance and avoiding the dumping of broken equipment (therefore, favoring ecological sustainability). Because the Action Framework follows the phases of a project, it does not consider elements related to sustainability after the closure of the project, such as the removal, recycling or disposal of the equipment. Nonetheless, it is worth noting that this aspect was also considered in this project; based on the energy-as-a-service model, the foundation (acciona.org) oversees the management of end-of-life equipment: upon end-of-life or end-of-service-life, acciona.org removes or replaces the SHSs and sends them to the supplier, which in turn manages their disposal.

\section{Discussion}

The first part of this research shows how the study of ATs has gained traction and relevance among scholars in the second decade of the twenty-first century. This is reflected in the increasing number of studies on the topic and the different changes that the definition of ATs has undergone recently. From 2015 onwards, the implementation of AT-based projects that are aligned with the SDGs has widened the gap between early theoretical 
approaches to the concept and the current perception of what ATs stand for. The definitions analyzed in the scoping review revealed that, from the perspective of the sequential development of projects involving ATs, the phases that are related to intrinsic characteristics of the technologies and necessary resources are contingent on the rest of the elements of the project. More precisely, the initial phase, which focuses on the needs and the context of the communities where the project will be implemented, shapes the characteristics of ATs. Therefore, technology-intensive cooperation projects should pay close attention to the initial stage and only then consider the possible technologies and associated resources necessary to successfully implement the project. In other words, projects that put technology first and people second may be more likely to fail.

The scoping review also showed that, unlike the approaches in theoretical studies, the definitions of ATs found in empirical research tend to focus on specific phases of the projects, and therefore lack a holistic view of AT-based actions, from their inception and needs assessment to the analysis of results and impact assessment. The analysis also uncovered a major gap in empirical studies, which are cross-sectional and where impact assessment is practically nonexistent. Measuring the impact of projects involving the implementation and use of ATs entails long-term measures, but all empirical studies provide a one-time picture of the project, most frequently taken at the completion of the implementation phase. This points out a need for longitudinal studies and the design of general models to assess the impact of AT-based projects.

There are two important elements for discussion from the case study. First, the definition of ATs from the scoping review allows us to assess whether the technology used in the Luz en Casa Amazonía project met the necessary requirements to qualify as AT. By observing the correspondence between the topics that ATs must cover and Luz en Casa Amazonía (Table 5), the project addressed a basic need of the community with a small-scale design approach. The project was people-oriented in that it put the community members at the center of the development process with the goal of improving their quality of life and reducing their vulnerability. The multi-stakeholder approach made it possible for the community to engage in the development and implementation of the management of the project. The result was a sustainable and maintainable implementation with a positive and quantifiable impact on the community.

Table 5. AT topics and the Luz en Casa Amazonía project.

\begin{tabular}{cc}
\hline People Oriented & Communities in the Napo, Ucayali and Amazonas River Basins \\
\hline Aligned with local needs & Sustainable energy access that improves the quality of life of the inhabitants \\
Small scale & Luz en Casa Napo Pilot 2016-61 households \\
Luz en Casa Napo 2017-350 households \\
Luz en Casa Napo 2018-1107 households
\end{tabular}

The second element for discussion refers to the extent to which the proposed Action Framework has helped improve the appropriateness of the technology in the case of $L u z$ en Casa Amazonía. While SHS might initially not qualify as affordable, simple, adaptable and local, the Action Framework helped make different decisions that facilitated the appropriation of the technology in the project (Table 6). For example, the cost of the systems would make them unaffordable to users, but this potential barrier has been overcome by the implementation of a fee-for-service model in which users assume only 20 percent of the cost of the electricity service tariff. Adaptability and simplicity of the systems have also 
been ensured by the implementation of PAYG systems and plug-and-play technologies, which overcome issues related to equipment transportation, training users on complex tasks or making them travel periodically to carry out maintenance of the system. Notably, the technological resources were not local due to the reasons mentioned in Section 4.2.2. However, the training of the different actors (again, based on a multi-stakeholder approach) ensures sustainability and maintenance during the useful life of the equipment.

Table 6. AT characteristics and the Luz en Casa Amazonía project.

\begin{tabular}{cc}
\hline Affordable & Fee-for-Service Model (FOSE) \\
\hline Simple & Plug-and-play systems, easy to repair and use \\
\hline Adaptable and flexible & Portable systems \\
\hline Local resources & All members of the local community are involved in ensuring the sustainability of the project. \\
However, no local devices are used in the project
\end{tabular}

While the initial definition of ATs $[16,27]$ considered it necessary to locally source the technologies in this kind of project, the technological evolution and other socio-politic and geographic constraints might make it difficult, and even impossible, to meet this characteristic. Considering this, it is essential to appropriate these technological resources through training in operation and maintenance to ensure the sustainability of the project.

From the above, and as the case study shows, the Action Framework can be an effective tool to facilitate the appropriateness of technology in technology-intensive cooperation projects, even when the initial requirements of ATs are not met.

\section{Conclusions}

This study addresses the challenge of appropriating technologies in technologyintensive, community-oriented projects, where the goal is to ensure the needs of the community are met in a sustainable way. To do so, we propose an Action Framework to guide the planning and implementation of technology-intensive cooperation projects, based on a comprehensive definition of ATs.

There are two main contributions to theory from this research. First, the literature review-based definition of ATs in this research provides a holistic view that differentiates between fundamental topics that ATs must cover in this kind of project and the intrinsic characteristics of the technologies for their appropriateness. As the case study demonstrates, the definition highlights essential elements of appropriateness and technical aspects that must be shaped during the project design and where different actions may be taken to facilitate appropriateness. Second, by combining the topics and characteristics of ATs with the phases of technology-intensive cooperation projects, from its inception to its completion and beyond, this study proposes an Action Framework that may be used as a reference in the design and implementation of such projects to ensure their appropriateness and sustainability. The Action Framework comprises four different phases (initiation, planning, execution and closure) and the different activities that must necessarily be carried out.

The application of the case study to a real AT-based project exemplified the usefulness of the Action Framework and evidenced that for technologies to be appropriated, it is most often necessary to make adjustments and provide different solutions (e.g., using different collaboration models, proposing innovative business models, simplification of technology use, training at different levels for effective knowledge transfer and management).

The study has some limitations. First, while scoping reviews are agile methods for clarification and identification of research gaps in a topic, the number of articles analyzed is lower than that of a systematic literature review, which comes at the peril of excluding additional research studies that could have enriched the findings from this study; thus, our preliminary results should be confirmed and expanded by such a systematic literature review. Second, the case study in this research is just one particular example of the application of the Action Framework; while we believe that its formulation is general 
enough to be applicable in most, if not all, technology-intensive cooperation projects, further evidence is necessary to support its generalizability. Third, by the way it was built, the Action Framework does not consider elements that extend beyond the closure of the project, which may be relevant from a sustainability perspective (e.g., management of end-of-service-life and the potential impact of the removal, recycling or disposal of equipment); future development of the Action Framework proposed in this study should seek to address this issue. Finally, the case study is not meant to provide a universal solution; as such, even when the application of the Action Framework to different projects followed the main guidelines provided in this research, the different decisions made to ensure appropriateness and sustainability do not necessarily have to be the same as the ones in our case study.

Author Contributions: Conceptualization, L.D.-R.-C., E.A.-N. and S.I.-P.; Methodology, L.D.-R.C. and E.A.-N.; Validation, L.D.-R.-C., E.A.-N. and S.I.-P.; Formal analysis, L.D.-R.-C. and S.I.P.; Investigation, L.D.-R.-C. and E.A.-N.; Resources, L.D.-R.-C. and S.I.-P.; writing-original draft preparation, L.D.-R.-C. and E.A.-N.; writing-review and editing, S.I.-P. and J.G.M.-F.; Visualization, L.D.-R.-C.; Supervision, S.I.-P. and J.G.M.-F.; Project administration, S.I.-P. and J.G.M.-F.; All authors have read and agreed to the published version of the manuscript.

Funding: This research received no external funding.

Institutional Review Board Statement: Not applicable.

Informed Consent Statement: Not applicable.

Data Availability Statement: Not applicable.

Conflicts of Interest: The authors declare no conflict of interest.

\section{References}

1. United Nations. Transformar Nuestro Mundo: La Agenda 2030 para el Desarrollo Sostenible; United Nations: New York, NY, USA, 2015. [CrossRef]

2. Emas, R. The Concept of Sustainable Development: Definition and Defining Principles. Brief GSDR 2015. [CrossRef]

3. Waas, T.; Hugé, J.; Verbruggen, A.; Wright, T. Sustainable development: A bird's eye view. Sustainability 2011, 3, 1637-1661. [CrossRef]

4. WCED. Our Common Future: Report of the World Commission on Environment and Development; WCED: Cape Town, South Africa, 1987; Volume 4. [CrossRef]

5. UN. From MDGs to SDGs. 2018. Available online: https://www.sdgfund.org/mdgs-sdgs (accessed on 20 December 2021).

6. UN. General Assembly Universal Declaration of Human Rights. 1948. Available online: https://www.refworld.org/docid/3ae6 b3712c.html (accessed on 20 December 2021).

7. Shin, H.; Hwang, J.; Kim, H. Appropriate technology for grassroots innovation in developing countries for sustainable development: The case of Laos. J. Clean. Prod. 2019, 232, 1167-1175. [CrossRef]

8. Wensing, A.J.; Wensing, E.J.; Virgo, M. Towards a core curriculum for civic engagement on appropriate technology: Characterizing, optimizing and mobilizing youth community service learning. Afr. J. Sci. Technol. Innov. Dev. 2018, 10, 867-877. [CrossRef]

9. Eras-Almeida, A.A.; Fernández, M.; Eisman, J.; Martín, J.G.; Caamaño, E.; Egido-Aguilera, M.A. Lessons learned from rural electrification experiences with third generation solar home systems in latin America: Case studies in Peru, Mexico, and Bolivia. Sustainability 2019, 11, 7139. [CrossRef]

10. Tharakan, J. Indigenous knowledge Systems-a rich appropriate technology resource. Afr. J. Sci. Technol. Innov. Dev. 2015, 7, 52-57. [CrossRef]

11. Schumacher, E.F. Small is Beautiful: Economics as if Poeple Mattered; Harper \& Row: New York, NY, USA, 1973.

12. Patnaik, J.; Bhowmick, B. Revisiting appropriate technology with changing socio-technical landscape in emerging countries. Technol. Soc. 2019, 57, 8-19. [CrossRef]

13. Verharen, C.; Kadoda, G.; Bugarin, F.; Fortunak, J.; Tharakan, J.; Schwartzman, D.; Wensing, E.; Middendorf, G. Appropriate technology and ethical obligations of the university: W.E.B. Du Bois on the Africana university missiont. Afr. J. Sci. Technol. Innov. Dev. 2017, 9, 467-477. [CrossRef]

14. Pattnaik, B.K.; Dhal, D. Mobilizing from appropriate technologies to sustainable technologies based on grassroots innovations. Technol. Soc. 2015, 40, 93-110. [CrossRef]

15. Sorensen, I.M.; McBean, E.A. Beyond appropriate technology: Social considerations for the sustainable use of Arsenic-Iron Removal Plants in rural Bangladesh. Technol. Soc. 2015, 41, 1-9. [CrossRef]

16. AI-Ali, S. Developing countries and technology transfer. Int. J. Technol. Manag. 1995, 10, 704-713. [CrossRef] 
17. Munn, Z.; Peters, M.D.J.; Stern, C.; Tufanaru, C.; McArthur, A.; Aromataris, E. Systematic review or scoping review? Guidance for authors when choosing between a systematic or scoping review approach. BMC Med. Res. Methodol. 2018, 18, 143. [CrossRef] [PubMed]

18. Grant, M.J.; Booth, A. A typology of reviews: An analysis of 14 review types and associated methodologies. Health Info. Libr. J. 2009, 26, 91-108. [CrossRef]

19. Anderson, S.; Allen, P.; Peckham, S.; Goodwin, N. Asking the right questions: Scoping studies in the commissioning of research on the organisation and delivery of health services. Health Res. Policy Syst. 2008, 6, 7. [CrossRef] [PubMed]

20. Weeks, L.C.; Strudsholm, T. A scoping review of research on complementary and alternative medicine (CAM) and the mass media: Looking back, moving forward. BMC Complement. Altern. Med. 2008, 8, 43. [CrossRef]

21. Arksey, H.; O’Malley, L. Scoping studies: Towards a methodological framework. Int. J. Soc. Res. Methodol. Theory Pract. 2005, 8 , 19-32. [CrossRef]

22. Moher, D.; Liberati, A.; Tetzlaff, J.; Altman, D.G.; Altman, D.; Antes, G.; Atkins, D.; Barbour, V.; Barrowman, N.; Berlin, J.A.; et al. Preferred reporting items for systematic reviews and meta-analyses: The PRISMA statement. PLoS Med. 2009 , 6, e1000097. [CrossRef]

23. Davidson Frame, J. Managing Projects in Organizations: How to Make the Best Use of Time, Techniques and People; Jossey Bass Business \& Management Series; Jossey Bass: San Francisco, CA, USA, 2003.

24. Darnall, R.; John, M.P. Project Management from Simple to Complex; University of Minnesota Libraries Publishing: Minneapolis, MN, USA, 2016.

25. Amor, J.P. Scheduling Programs with Repetitive Projects Using Composite Learning Curve Approximations. Proj. Manag. J. 2002, 33, 16-29. [CrossRef]

26. Bhattacharjya, B.R.; Kakoty, S.K.; Singha, S. A feedback mechanism for appropriate technology development and dissemination: Case study approach. Technol. Soc. 2019, 57, 104-114. [CrossRef]

27. Segal, A. Appropriate Technology-The African Experience. J. Asian Afr. Stud. 1992, 27, 124-133. [CrossRef]

28. Kaplinsky, R. Schumacher meets schumpeter: Appropriate technology below the radar. Res. Policy 2011, 40, 193-203. [CrossRef]

29. Guimón, J.; Guimón, P. How ready-to-use therapeutic food shapes a new technological regime to treat child malnutrition. Technol. Forecast. Soc. Change 2012, 79, 1319-1327. [CrossRef]

30. Verharen, C.; Tharakan, J.; Middendorf, G.; Castro-Sitiriche, M.; Kadoda, G. Introducing Survival Ethics into Engineering Education and Practice. Sci. Eng. Ethics 2013, 19, 599-623. [CrossRef] [PubMed]

31. Park, E.; Ohm, J.Y. Appropriate Technology for Sustainable Ecosystems: Case Studies of Energy Self-Reliant Villages and the Future of the Energy Industry. Sustain. Dev. 2015, 23, 74-83. [CrossRef]

32. Tharakan, J. Integrating indigenous knowledge into appropriate technology development and implementation. Afr. J. Sci. Technol. Innov. Dev. 2015, 7, 364-370. [CrossRef]

33. Botchie, D.; Sarpong, D.; Bi, J. A comparative study of appropriateness and mechanisms of hard and soft technologies transfer. Technol. Forecast. Soc. Change 2018, 131, 214-226. [CrossRef]

34. Lashitew, A.A.; van Tulder, R.; Liasse, Y. Mobile phones for financial inclusion: What explains the diffusion of mobile money innovations? Res. Policy 2019, 48, 1201-1215. [CrossRef]

35. INEI. Status of the Peruvian Population. 2020. Available online: https://www.inei.gob.pe/estadisticas/indice-tematico/ population/ (accessed on 20 December 2021).

36. Donahue, J.D.; Zeckhauser, R.J. Public-Private Collaboration. Oxf. Handb. Public Policy 2009, 496-525. [CrossRef]

37. Giraldo, J.M.M. El Acceso Universal a la Energía en la Amazonia, Una Visión de la Fundación INGENIEROS de ICAI Para el Desarrollo. 2018. Available online: https:/ / web.archive.org/web/20210103193809/https://www.icai.es/articulo-revista/elacceso-universal-a-la-energia-en-la-amazonia-una-vision-de-la-fundacion-ingenieros-de-icai-para-el-desarrollo/ (accessed on 18 October 2021). 